\title{
IMPLEMENTASI HSE PASSPORT DI PT. PERTAMINA EP ASSET 2 PRABUMULIH FIELD
}

\author{
Dina Putri Yulianti \\ Puskesmas Garuda \\ Jl. Dadali No.6, Garuda, Andir, Kota Bandung, Jawa Barat \\ Email: dinaputriyulianti@gmail.com
}

\begin{abstract}
Oil and gas industry is high capital, technology and risk. Therefore a program is needed to monitor workers such as HSE Passport. HSE Passport is a book that contain orientation, training and certification that has been obtained and also contain the latest health condition report of the workers. HSE Passport will facilitate chief to assign the worker capability to work where and when. Purpose of this research isto analyze the implementation of HSE Passport as work permit in PT Pertamina EP Prabumulih Field. This study used cross sectional descriptive design. Variable in this research were HSE Passport and work permit. The population are 443 workers. Sampling technique used accidental sampling so that samples in this research were 42 consists of 21 workers and 21 contractor. Results of this study that implementations of HSE Passport has not been fully implemented. Workers did not understand the importance of HSE Passport and also regulations on HSE Passport had not been implemented strictly such as banned to access work sites. If executed according to the procedure, it will helped reduce risk of occupational accident. Suggestions for the company that its necessary to set strict sanctions in case of violation and there should be an evaluation comprehensive during Mandatory training.
\end{abstract}

Keywords: HSE Passport, occupational accident, worker

\begin{abstract}
ABSTRAK
Industri migas merupakan industri yang tinggi modal, tinggi teknologi, serta tinggi risiko. Karena itu perlu program yang dapat memonitoring pekerja seperti HSE Passport. HSE Passport adalah buku yang berisi orientasi, pelatihan, sertifikasi yang telah diperoleh dan kondisi kesehatan dari pekerja. Adanya HSE Passport, akan memudahkan atasan untuk menetapkan pekerja tersebut mampu bekerja dimanapun dan kapanpun. Tujuan dari penelitian ini adalah menganalisis implementasi HSE Passport di PT. Pertamina EP Prabumulih Field. Berdasarkan rancangan penelitian, penelitian ini menggunakan penelitian deskriptif, ditinjau dari waktu termasuk penelitian cross sectional. Populasi penelitian adalah pekerja dan pekarya di PT. Pertamina EP Prabumulih Field berjumlah 443 pekerja. Teknik pengambilan data menggunakan accidental sampling sehingga jumlah sampel menjadi 42 pekerja terdiri dari 21 pekerja dan 21 kontraktor. Hasil Implementasi HSE Passport di PT. Pertamina EP Prabumulih Field belum berjalan sepenuhnya. Pekerja belum memahami pentingnya HSE Passport. Peraturan tentang HSE Passport belum dilaksanakan secara tegas. Apabila dijalankan sesuai dengan prosedur, akan membantu mengurangi risiko kecelakaan kerja. Saran untuk PT. Pertamina EP Prabumulih adalah perlu adanya pengaturan sanksi yang tegas seperti larangan memasuki lokasi kerja dan perlu diadakan evaluasi pemahaman HSE Passport pada saat pelatihan Mandatory.
\end{abstract}

Kata kunci: HSE Passport, kecelakaan kerja, tenaga kerja

\section{PENDAHULUAN}

Industri migas merupakan industri yang padat modal (high cost), padat teknologi (high technology) serta padat risiko (high risk). Hal ini dikarenakan industri migas berkaitan dengan zat-zat yang berbahaya dan mudah terbakar (gas dan oil), proses eksploitasi yang berisiko tinggi, menggunakan fasilitas dan konstruksi yang besar serta menggunakan banyak man power.

Perusahaan-perusahaan migas mulai memberlakukan sistem pengawasan dan pembinaan untuk menunjang keselamatan dan kesehatan para tenaga kerjanya sehingga nantinya mampu menghasilkan SDM yang berkompeten di bidang minyak dan gas. Melalui kegiatan diklat, pelatihan dan pemeriksaan kesehatan diharapkan para SDM yang memiliki kualifikasi dan kompetensi terstandarkan dapat mengelola kekayaan migas secara profesional.

Pemerintah telah menetapkan peraturan yang mewajibkan perusahaan untuk melakukan pemeriksaan kesehatan pada calon pekerja yang tertuang dalam UU No. 1 Tahun 1970 tentang Keselamatan Kerja pasal 8 ayat 1 yang berbunyi 
"Pengurus diwajibkan memeriksakan kesehatan badan, kondisi mental dan kemampuan fisik dari tenaga kerja yang akan diterimanya maupun akan dipindahkan sesuai dengan sifat-sifat pekerjaan yang diberikan padanya". Dan pasal 9 ayat 3 yang berbunyi "Pengurus diwajibkan menyelenggarakan pembinaan bagi semua tenaga kerja yang berada di bawah pimpinannya, dalam pencegahan kecelakaan dan pemberantasan kebakaran serta peningkatan keselamatan dan kesehatan kerja, pula dalam pemberian pertolongan pertama pada kecelakaan. Hal inilah yang mendasari perusahaan melakukan pemeriksaan kesehatan, orientasi maupun pelatihan untuk mencegah dan menanggulangi risiko kecelakaan kerja.

Menurut Suma'mur (2009), kecelakaan disebabkan oleh dua hal yaitu tindak perbuatan manusia yang tidak memenuhi keselamatan (unsafe human action) dan keadaan-keadaan lingkungan yang tidak aman (unsafe condition). Menurut Winarsunu (2008), pandangan kecelakaan kerja dikelompokkan menjadi 2 yaitu: pandangan pesimistis dan optimistis. Pandangan pesimistis adalah pandangan yang menganggap kecelakaan kerja sebagai suatu kejadian yang tidak dapat dikontrol dan diprediksikan yang lebih disebabkan oleh faktor ketidakberuntungan atau oleh faktorfaktor yang tidak dapat diprediksi. Sedangkan pandangan optimistis adalah pandangan yang menganggap kecelakaan kerja sebagai suatu kejadian yang sangat merugikan yang dapat di antisipasi kemunculannya dan diamati sebabnya.

Sebagai wujud tanggung jawab terhadap tenaga kerja, PT Pertamina EP senantiasa menempatkan aspek keselamatan dan kesehatan kerja sebagai faktor yang paling utama. Hal ini merupakan komitmen perusahaan untuk menjalankan kegiatan operasi yang bertanggung jawab. Sesuai rencana strategis PT Pertamina EP untuk menjadi perusahaan minyak dan gas berkelas dunia (world class company), fungsi HSSE telah melakukan beberapa langkah strategis dengan indikator: Tanpa Kecelakaan (Zero Accident), Ramah Lingkungan (Zero Discharge, Zero Flaring dan Konservasi Energi), Tanpa Gangguan Operasi dan Tanpa Penyakit Akibat Kerja.

Perusahaan sangat paham bahwa faktor tersebut dapat mempengaruhi keberlangsungan usaha perusahaan. Oleh karena itu, PT Pertamina EP juga bertujuan untuk menjadikan keselamatan dan kesehatan kerja dan lindung lingkungan (health, safety, security \& environment-HSSE) sebagai

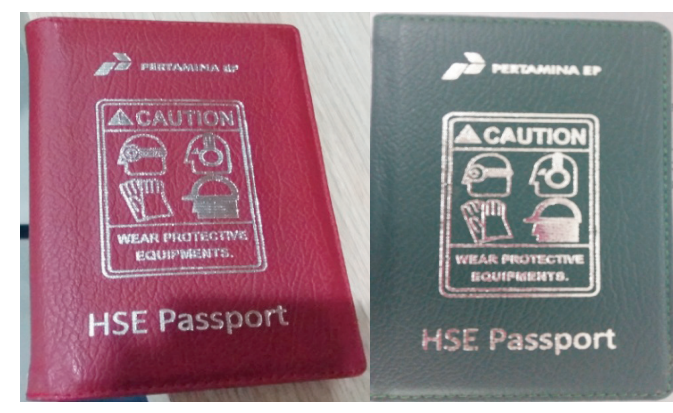

Gambar 1. HSE Passport Pekerja dan Pekarya/ Mitra kerja/ Kontraktor

budaya perusahaan melalui program HSE Excellence yang dimulai dengan HSE Road To Zero Program. Salah satu programnya adalah HSE Passport.

HSE Passport adalah dokumen yang dikeluarkan oleh PT. Pertamina EP yang berisi tentang data diri pegawai, mitra kerja dan tamu Perusahaan termasuk sertifikasi profesi, riwayat pelatihan, orientasi dan aktivitas HSE yang pernah diikuti, medical check-up serta riwayat penghargaan dan catatan khusus lainnya. HSE Passport merupakan salah satu syarat memasuki wilayah dan melakukan kegiatan di lingkungan kerja Pertamina EP bagi pekerja, pekarya/mitra kerja dan tamu.

Buku HSE Passport terbagi menjadi 3 jenis yaitu: HSE Passport untuk pekerja (warna merah), HSE Passport untuk pekarya/mitra kerja/ kontraktor (warna hijau) dan HSE Passport untuk tamu (warna biru). (TKO Penerapan HSE Passport, 2012). Fungsi utama Passport ini adalah untuk mengetahui apakah pekerja yang masuk ke lokasi produksi tersebut fit to work dan kompeten dengan pekerjaannya.

Tujuan proses penerapan HSE Passport adalah untuk: mencegah/mengurangi terjadinya kegagalan, kecelakaan yang dapat mengakibatkan kerugian, baik pada peralatan ataupun pada pekerja; mengidentifikasi kualifikasi pengetahuan HSE individu dan aspek HSE lainnya; memastikan bahwa individu yang memasuki wilayah kerja dan atau melakukan kegiatan di Pertamina EP memenuhi aspek HSE, kompetensi dan kesehatan yang diisyaratkan (TKO Penerapan HSE Passport, 2012).

Setiap pemegang HSE Passport memiliki pengawas yang disebut dengan User, yang mana akan memeriksa dan mengevaluasi HSE Passport setiap 6 bulan sekali. Setiap pemegang HSE Passport memiliki User yang berbeda dilihat dari status pemegang Passport dengan keterangan yang dapat dilihat pada tabel 1. 
Tabel 1. User (atasan) pemegang Passport

\begin{tabular}{ll}
\hline Pemegang Passport & \multicolumn{1}{c}{ User } \\
\hline Pekerja & Atasan \\
Pekarya & Pengawas Pekerjaan \\
Mitra Kerja & Pengawas Pekerjaan \\
Tamu & Personel Fungsi yang \\
& dikunjungi \\
\hline
\end{tabular}

User nantinya yang akan menetapkan pemenuhan kebutuhan Awareness HSE seperti pelatihan atau sertifikasi bagi para pekerjanya (TKO Penerapan HSE Passport, 2012)

HSE Passport seyogyanya dimiliki oleh seluruh pekerja, mitra karya dan tamu yang bekerja pada lokasi dengan risiko bahaya tinggi. HSE Passport berlaku ketika akan memasuki wilayah operasi kegiatan PT. Pertamina EP. HSE Passport ini berlaku untuk seluruh pekerja, pekarya dan mitra kerja di seluruh fasilitas atau instalasi produksi sumur, stasiun pengumpul (SP), stasiun pengumpul umum (SPU), pusat penampung produksi (PPP), workshop, bengkel, power plant, maupun gudang.

Tujuan dari penelitian ini adalah menganalisis implementasi HSE Passport di PT. Pertamina EP Prabumulih Field. Dikarenakan program baru, maka HSE Passport perlu dimonitoring pelaksanaannya.

\section{METODE}

Berdasarkan metodenya, penelitian ini menggunakan penelitian observasional karena peneliti hanya melakukan observasi, tanpa memberikan intervensi pada variabel yang akan diteliti. Berdasarkan waktu penelitian, penelitian ini bersifat cross sectional, dimana pengukurannya hanya satu kali saja. Berdasarkan rancangan penelitian, penelitian ini menggunakan penelitian deskriptif untuk mengetahui implementasi HSE Passport sebagai sistem ijin kerja di PT. Pertamina EP Prabumulih Field. Populasi dari penelitian ini yaitu pekerja dan pekarya/mitra kerja PT. Pertamina EP Asset 2 Prabumulih Field berjumlah 443 orang. Teknik pengambilan sampel menggunakan accidental sampling yaitu siapa saja yang secara kebetulan/incidental bertemu peneliti dapat digunakan sebagai sampel bila dipandang orang yang kebetulan ditemui itu cocok sebagai sumber data. Sampel penelitian ini berjumlah 42 yang terdiri dari 21 pekerja dan 21 pekarya/kontraktor.
Lokasi penelitian adalah di PT. Pertamina EP Asset 2 Prabumulih Field. Waktu pengambilan data dilaksanakan pada bulan September-Oktober 2016. Pemantauan implementasi HSE Passport dilakukan oleh pengawas setiap 6 bulan sekali dengan menggunakan lembar peninjauan. Data yang digunakan dalam penelitian adalah data primer dan sekunder. Cara pengumpulan data-data primer dengan menggunakan lembar observasi yang di adaptasi dari lembar peninjauan pengawas dan indepth interview untuk mengetahui lebih dalam tentang implementasi HSE Passport di perusahaan. Sedangkan data sekunder berupa profil perusahaan, prosedur Tata Kerja Organisasi (TKO) HSE Passport, HSE Passport pekerja dan pekarya/mitra kerja PT. Pertamina EP Asset 2 Prabumulih Field. Setelah hasil data primer dan data sekunder diperoleh, data kemudian diolah dengan cara membandingkan kesesuaian penerapannya di lapangan dengan prosedur yang berlaku. Setelah itu, data yang diperoleh akan diolah dan dianalisis secara deskriptif dengan menjabarkan hasil yang ada. Dari sini peneliti dapat mengetahui tentang implementasi HSE Passport di PT. Pertamina EP Asset 2 Prabumulih Field.

\section{HASIL}

\section{Implementasi HSE Passport pada Pekerja PT. Pertamina EP}

Seluruh pekerja PT. Pertamina EP telah memiliki HSE Passport. Tetapi tidak semua pekerja membawa HSE Passport ketika memasuki wilayah kerja. Pekerja hanya memberikan Name Tag di petugas keamanan bila akan memasuki wilayah kerja.

Seperti ketika ada pekerja baru/mutasi di perusahaan, mereka akan menerima orientasi aspek HSE. Tetapi materi yang biasanya diberikan hanya sebatas HSE Awareness, penggunaan APD, dan tanggap darurat. Selain orientasi aspek HSE, seluruh pekerja wajib mengikuti Mandatory training. Materi yang wajib diberikan pada pekerja adalah BST (Basic Safety Training) dan Safe Lifting and Rigging. Sedangkan pelatihan lainnya disesuaikan dengan setiap pekerjaan, Refreshment Mandatory training dilakukan setiap 3 tahun sekali.

Sebagian besar pekerja (63\%) telah mengikuti sertifikasi sesuai dengan profesinya. Tetapi hal itu tidak tertulis pada lembar pencatatan sertifikasi profesi. Meskipun begitu, user selalu memastikan 
dan mengevaluasi pemenuhan kebutuhan bawahannya.

Untuk evaluasi dan pemeriksaan Passport, seharusnya user berkoordinasi dengan HSSE setidaknya setiap 6 bulan sekali, tetapi sampai saat ini HSE Passport pekerja tidak pernah diminta untuk diperiksa dan dievaluasi. Sehingga tidak ada catatan terbaru mengenai pelatihan, sertifikasi maupun pemeriksaan kesehatan yang telah diterima pekerja. Lembar peninjauan yang seharusnya di isi oleh user dalam HSE Passport sering kali kosong. Lembar peninjauan nantinya akan digunakan untuk membuat laporan implementasi oleh HSSE dan diserahkan ke komite HSE.

\section{Implementasi HSE Passport pada Pekarya/Mitra Kerja/Kontraktor}

Sampai saat ini, sebagian besar pekarya/mitra keja (65\%) belum memiliki HSE Passport. Hal tersebut dikarenakan terkendala jumlah pekarya/ mitra kerja PT. Pertamina EP yang banyak, sehingga pemenuhan HSE Passport sedikit terhambat. Bila memasuki lokasi kerja terutama di sumur produksi, pekarya harus menyerahkan HSE Passport dan surat tugas/surat ijin masuk lokasi (SIM L). Tetapi apabila pekarya belum memiliki HSE Passport, maka cukup dengan menyerahkan surat tugas/surat ijin masuk lokasi (SIM L).

Bila belum memiliki Passport, pekarya dapat menulis formulir pengajuan HSE Passport yang nanti akan diterbitkan fungsi HSSE. Setelah terbit HSE Passport, User (Pengawas Pekerjaan) akan memeriksa HSE Passport dan merencanakan serta membuat formulir perencanaan pemenuhan seperti orientasi aspek HSE, pelatihan HSE wajib, sertifikasi dan pemeriksaan kesehatan sesuai dengan kebutuhan. User menyerahkan formulir perencanaan kepada HR (Human Resources) sehingga HR akan berkoordinasi dengan user, HSSE dan kontraktor untuk merencanakan pemenuhan kebutuhan pelatihan dan pemeriksaan kesehatan sesuai formulir yang diterima.

Dari 8 materi program orientasi aspek HSE hanya SIKA (Surat Ijin Kerja Aman), JSA (Job Safety Analysis), dan MSDS (Material Safety Data Sheet) saja yang diterima oleh pekarya/mitra kerja. Seluruh pekarya wajib mengikuti Mandatory training. Materi yang wajib diberikan pada pekarya adalah BST (Basic Safety Training) dan Safe Lifting and Rigging. Sedangkan pelatihan lainnya disesuaikan dengan pekerjaan masing. Pelatihan yang tercatat dalam HSE Passport biasanya

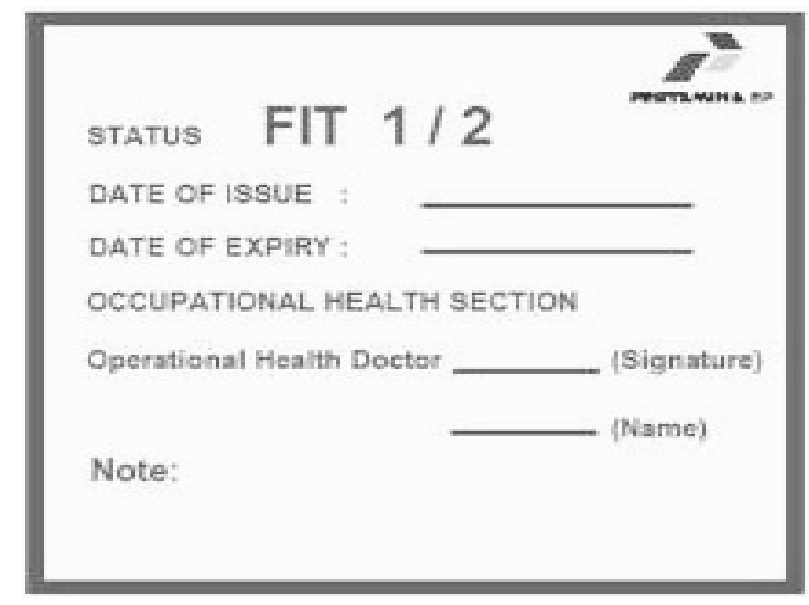

Gambar 2. Stempel Penilaian Pemeriksaan Kesehatan

pelatihan yang dilakukan selama bekerja sama dengan PT. Pertamina EP, pelatihan sebelum bekerja sama biasanya tidak tercatat.

Pekarya/mitra kerja melakukan pemeriksaan sendiri selama ini kemudian hasilnya di serahkan pada bagian medic PT. Pertamina EP. Petugas pada bagian medic yang akan bertanggung jawab menuliskan status kesehatan para pekerja pada HSE Passport. Apakah status pekerja tersebut fit to work (kode 1) atau fit with note (kode 2).

HSE Passport pekarya/mitra kerja terakhir di update tahun 2014. Seharusnya setiap 6 bulan sekali di evaluasi dan diperiksa oleh atasan pekerja. Bulan September 2016 ini, HSE Passport para pekarya/ mitra kerja telah dikumpulkan untuk dievaluasi dan diperiksa. HSE coordinator merekapitulasi, mengevaluasi dan mendokumentasikan laporan peninjauan kemudian memberikan umpan balik

Tabel 2. Matriks Batasan Pemenuhan Awareness HSE

\begin{tabular}{lcl}
\hline Aspek & Nilai & Keterangan \\
\hline \multirow{2}{*}{$\begin{array}{l}\text { Durasi } \\
\text { Kegiatan }\end{array}$} & 1 & Kegiatan $<$ jam \\
\cline { 2 - 3 } & 2 & $\begin{array}{l}\text { Kegiatan } 8 \text { jam s/d 30 hari } \\
\text { kalender }\end{array}$ \\
\hline $\begin{array}{l}\text { Risiko } \\
\text { Kegiatan } \\
\text { (mengacu }\end{array}$ & 1 & Kegiatan $>30$ hari kalender \\
\cline { 2 - 3 } $\begin{array}{l}\text { Pedoman } \\
\text { CSMS) }\end{array}$ & 2 & Menengah \\
\hline & 3 & Tinggi \\
\hline $\begin{array}{l}\text { Lokasi } \\
\text { Kegiatan }\end{array}$ & 1 & Daerah Tidak berbahaya \\
\cline { 2 - 3 } & 2 & Daerah berbahaya divisi II \\
\hline
\end{tabular}


Tabel 3. Risk Matriks

KEPARAHAN

$\begin{array}{llll}\text { Sangat Ringan } & \text { Ringan } & \text { Sedang } & \text { Berat }\end{array}$

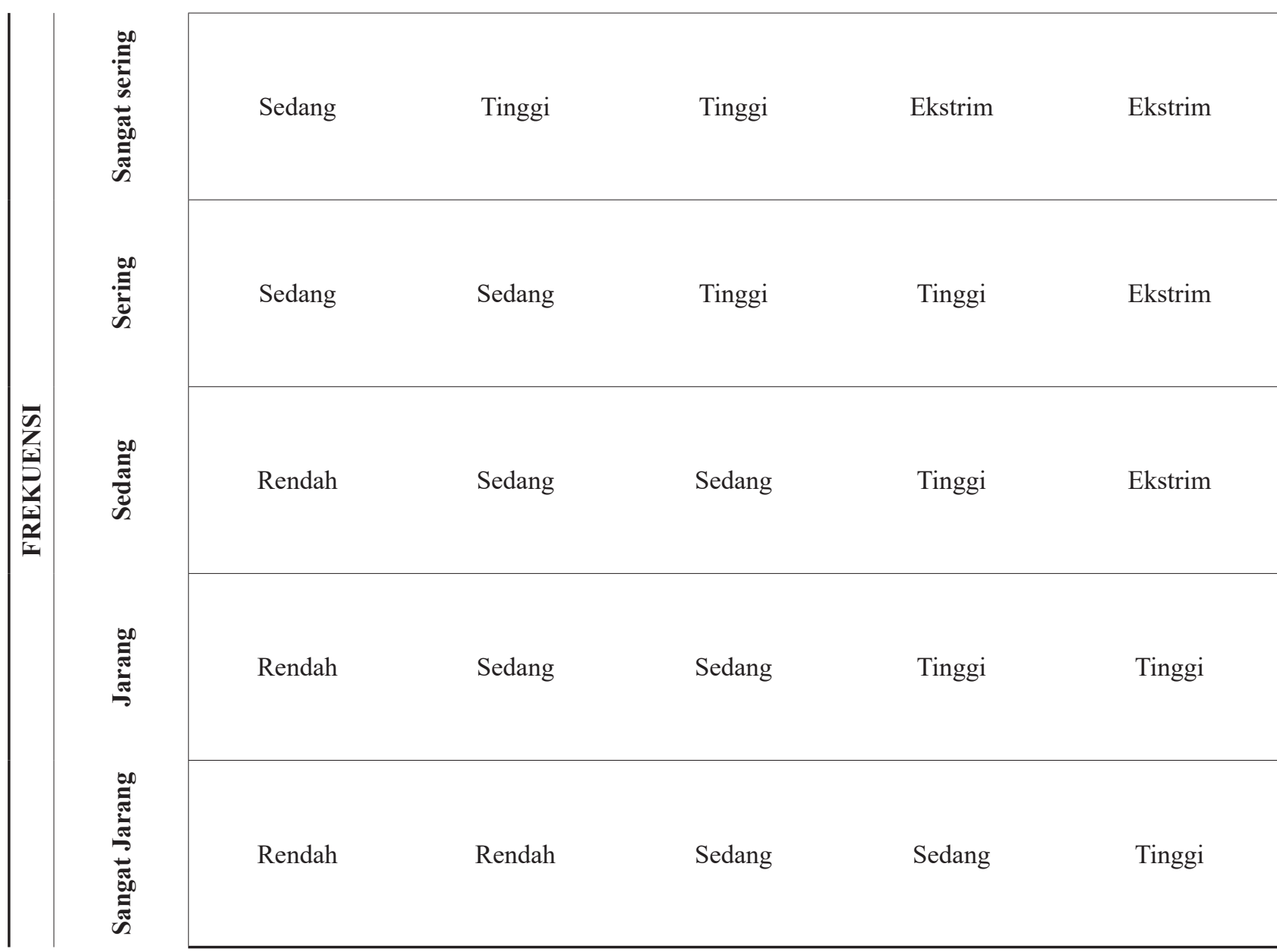

kepada user dan HR. HSE koordinator membuat laporan implementasi untuk diserahkan ke Komite HSE.

\section{Implementasi HSE Passport pada Tamu Eksternal}

Bila datang ke wilayah kerja PT. Pertamina EP, Tamu wajib melapor dan menjelaskan tujuan kedatangan dan siapa yang akan ditemui. Secara singkat ke fungsi Sekuriti Tamu akan menyerahkan surat tugas/surat keterangan pada user dan user akan mengonfirmasi kegiatan yang akan dilakukan kemudian melakukan evaluasi matriks batasan pemenuhan Awareness HSE untuk tamu seperti yang ada pada tabel 2 .

Durasi kegiatan bisa dilihat dari berapa lama seseorang tersebut akan berada dalam lokasi kegiatan kerja PT. Pertamina EP. Untuk menetapkan kategori
Tabel 4. Klasifikasi Daerah Berbahaya berdasarkan Divisi

\begin{tabular}{cl}
\hline \multicolumn{1}{c}{ Divisi } & \multicolumn{1}{c}{ Keterangan } \\
\hline Divisi 0 & $\begin{array}{l}\text { Daerah yang selalu mengandung gas } \\
\text { berbahaya }\end{array}$ \\
\hline Divisi 1 & $\begin{array}{l}\text { Daerah yang mungkin mengandung gas } \\
\text { berbahaya pada keadaan normal }\end{array}$ \\
\hline Divisi 2 & $\begin{array}{l}\text { Daerah yang mengandung gas yang } \\
\text { berbahaya pada kondisi yang tidak } \\
\text { normal. }\end{array}$ \\
\hline
\end{tabular}

risiko seseorang apakah risiko rendah, sedang, tinggi ataupun ekstrem dapat menggunakan metode Risk Matriks seperti pada tabel 3.

Sedangkan untuk menentukan, apakah lokasi yang dikunjungi termasuk klasifikasi daerah berbahaya atau tidak, dapat dilihat pada tabel 4 . 
Cara menghitung hasil dari matriks batasan pemenuhan awareness HSE adalah nilai dari aspek durasi, risiko dan lokasi digabungkan. Hasil akhir dari penggabungan tersebut dapat digunakan sebagai acuan untuk memberikan orientasi atau pelatihan bagi tamu tersebut.

Tamu wajib mengisi formulir waiver sebagai pengganti pemeriksaan kesehatan atau dapat menyerahkan surat keterangan sehat. Formulir waiver akan divalidasi dokter Perusahaan apabila terdapat riwayat penyakit yang dikhawatirkan mengganggu pekerjaan. Tamu yang datang untuk audit atau inspeksi tidak dibuatkan HSE Passport karena tugasnya tidak bersinggungan dengan pekerjaan berbahaya. User melaksanakan pemenuhan Awareness HSE dan menerbitkan Passport jika diperlukan sesuai dengan hasil evaluasi Matriks batasan pemenuhan Awareness HSE untuk tamu. Tetapi sampai saat ini belum ada tamu yang memerlukan HSE Passport, jadi PT. Pertamina EP belum mengeluarkan HSE Passport untuk tamu.

\section{PEMBAHASAN}

Tujuan diberlakukannya HSE Passport adalah sebagai pengendalian keselamatan dan kesehatan kerja secara administratif bagi setiap pekerja dalam melakukan kegiatan di PT. Pertamina EP untuk mengantisipasi potensi bahaya, mencegah serta meminimalisir risiko terjadinya insiden, agar dapat melaksanakan pekerjaan dengan aman, mencegah/mengurangi terjadinya kegagalan dan kecelakaan yang dapat mengakibatkan kerugian baik pada peralatan, manusia, ataupun lingkungan serta menciptakan lingkungan kerja yang aman dan selamat.

Risiko kecelakaan kerja dapat dicegah dan ditanggulangi dengan menciptakan lingkungan kerja yang sesuai dengan keselamatan dan kesehatan kerja. HSE Passport sebagai sistem ijin kerja merupakan langkah awal dari segala pekerjaan yang akan di lakukan dengan mempertimbangkan kapasitas pekerja baik secara kemampuan maupun kesehatan.

Di dalam HSE Passport terdapat catatan tentang orientasi dan pelatihan yang telah diterima, sertifikasi yang telah di dapat, dan kondisi kesehatan terkini dari pekerja. Dengan pedoman catatan yang ada di dalam Passport, akan memudahkan atasan untuk menetapkan apakah pekerja tersebut mampu bekerja di manapun dan kapan pun. Selain itu juga terdapat tabel pemenuhan kebutuhan yang nantinya akan di isi oleh user sesuai dengan kebutuhan pekerjaan masing-masing.

Orientasi aspek HSE diberikan pada pekerja/ pekarya/kontraktor dan tamu pada hari pertama sebelum dimulai pekerjaan dan dilaksanakan di kantor. Durasi Orientasi adalah 3 jam sampai dengan $8 \mathrm{jam}$. Beberapa materi tentang orientasi diantaranya adalah: (1) HSE Awareness, (2) Penggunaan APD, (3) SIKA, (4) JSA, (5) Keselamatan Berkendara, (6) Tanggap Darurat, (7) P3K, (8) MSDS (TKO Safety briefing, Induksi dan Orientasi Aspek HSE, 2015)

Selain orientasi aspek HSE, Mandatory training merupakan pelatihan yang wajib diikuti oleh seluruh pekarya di PT. Pertamina EP guna meningkatkan kompetensinya. Pelatihan tersebut disesuaikan dengan area kerja pemegang HSE Passport. Durasi satu judul training HSE Wajib (Mandatory) minimum adalah 8 jam. Pelatihan HSE Wajib (Mandatory) merupakan pelatihan HSE yang meliputi: (1) Basic Safety Training; (2) Behavior Based Safety; (3) First Aid Level 1; (4) Emergency Preparedness \& Fire fighting; (5) Keselamatan Berkendara; (6) Perlindungan dan Pengelolaan Lingkungan; (7) Fire and Safety; (8) Safe Lifting and Rigging; (9) Basic Sea Survival; (10) Helicopter Underwater Escape Training.

Materi Mandatory training di sampaikan oleh safety staff PT. Pertamina EP sedangkan sertifikasi bagi para pekerja diberikan oleh Pertamina HSE Training Center yang berlokasi di Sungai Gerong, Palembang, Sumatera Selatan, Indonesia. Yang mana adalah pusat pelatihan kesehatan, keselamatan kerja, dan lingkungan dengan fasilitas terlengkap di Asia. Pertamina HSE TC bekerja sama dengan Kementerian Ketenagakerjaan untuk menyelenggarakan sertifikasi-sertifikasi ahli pemadam, ahli $\mathrm{K} 3$, gas tester, fall protection training dan lain sebagainya.

Pada pekarya/mitra kerja/kontraktor, perusahaan juga memberikan pelatihan dan sertifikasi yang sama dengan pekerja sesuai dengan posisi dan profesi masing-masing. Sehingga para pekarya/kontraktor mengetahui risiko pekerjaan yang akan dihadapi dengan diberikannya pelatihan tersebut.

Menurut penelitian yang dilakukan oleh Piri (2012), bahwa semakin sering pekerja menerima pelatihan maka nilai kecelakaan kerja akan semakin rendah. Sehingga dapat diambil kesimpulan bahwa pelatihan kerja memiliki pengaruh positif terhadap kecelakaan kerja.

Banyak dari pekerja/pekarya yang sudah melakukan pelatihan tetapi belum tercatat pada 
HSE Passportnya. Seperti halnya pencatatan pada kolom sertifikasi pekerja. Dari hasil indepth interview dengan safety staff, banyak HSE Passport pekerja yang tidak ter-update pelatihannya adalah karena HSE Passport hilang atau para pekerja lupa membawa HSE Passport pada waktu pelatihan. Sehingga HSE Passport tidak dapat divalidasi oleh fungsi HR dan HSSE.

Selain orientasi dan Mandatory training, pemeriksaan kesehatan merupakan hal yang wajib diikuti oleh seluruh pekerja maupun pekarya. Menurut penelitian yang dilakukan oleh Piri (2012), bahwa semakin tinggi faktor kesehatan pekerja maka akan dapat menurunkan faktor kecelakaan kerja pada pekerja. Begitu juga penelitian yang dilakukan oleh Ilvani dan Nugraheni (2013), bahwa kesehatan kerja mempunyai pengaruh positif terhadap kinerja karyawan secara signifikan. Hal ini berarti semakin baik program kesehatan kerja di suatu perusahaan, maka semakin baik kinerja karyawannya.

Pemeriksaan kesehatan pada pekerja/pekarya/ kontraktor ada 2 yaitu pemeriksaan kesehatan awal dan berkala. Pemeriksaan kesehatan awal diberikan ketika akan menjadi pekerja di PT. Pertamina EP sedangkan pemeriksaan kesehatan berkala dilakukan rutin setiap 1 tahun sekali. Menurut Peraturan Menteri Tenaga Kerja Dan Transmigrasi No. Per.02/ Men/1980 Pasal 1, Pemeriksaan kesehatan sebelum kerja adalah pemeriksaan kesehatan yang dilakukan oleh dokter sebelum seorang tenaga kerja diterima untuk melakukan pekerjaan sedangkan pemeriksaan kesehatan berkala adalah pemeriksaan kesehatan pada waktu-waktu tertentu terhadap tenaga kerja yang dilakukan oleh dokter.

Hasil dari pemeriksaan kesehatan akan menentukan apakah status pekerja pada HSE Paspornya akan fit/unfit. Fit 1 berarti Fit To Work yaitu karyawan tersebut dapat melakukan pekerjaan apa saja dan dapat ditempatkan di manapun. Fit 2 berarti Fit with note yaitu terdapat keterbatasan kesehatan pada karyawan tersebut sehingga hanya dapat ditempatkan di posisi tertentu. Misalnya pekerja dengan TB paru, asma, diabetes melitus, hipertensi dan penyakit jantung koroner.

Selain dua status tersebut, sebenarnya masih ada status lain yaitu temporary unfit dan permanently unfit. Temporary unfit adalah terdapat keterbatasan kesehatan pada karyawan tersebut sehingga karyawan butuh pengobatan sebelum bekerja bila status pekerja temporary unfit, maka HSE Passport tidak dikeluarkan. Pekerja harus menerima pengobatan terlebih dahulu selama 14 hari. Setelah itu akan dilakukan assessment. Bila pekerja tersebut telah sembuh, akan dikeluarkan HSE Passport dengan status fit with not. Apabila belum sembuh, maka pekerja tersebut harus menerima pengobatan kembali.

Sedangkan permanently unfit adalah pekerja tersebut tidak diperkenankan masuk ke dalam lokasi operasi kerja PT. Pertamina EP. Akan dilakukan rotasi kerja yang sesuai misalnya menempatkan pekerja tersebut pada pekerjaan administratif.

Stempel penilaian pemeriksaan kesehatan harusnya diperbarui setiap tahun tapi sampai saat ini, stempel yang ada di dalam HSE Passport pekerja belum pernah diperbarui. Padahal pemeriksaan pada pekerja tiap tahun akan berbeda. Sehingga kemungkinan dapat mempengaruhi kinerja, terlebih lagi bagi para pekerja yang bekerja di bagian field, dimana risiko pekerjaannya lebih besar.

Jika HSE Passport wajib dimiliki oleh pekerja dan pekarya/mitra kerja, lain halnya dengan tamu. Tidak semua tamu diharuskan memiliki HSE Passport. Tamu yang datang ke PT. Pertamina EP terlebih dahulu akan dievaluasi dengan menggunakan Matriks Batasan Pemenuhan Awareness HSE. Matriks ini berisi beberapa aspek yaitu seperti durasi kegiatan, risiko kegiatan dan lokasi dimana tamu tersebut akan melakukan kegiatan, yang mana dari ketiga aspek tersebut kemudian dinilai untuk memenuhi kebutuhan Awareness dan untuk mengetahui apakah perlu atau tidaknya dikeluarkan HSE Passport.

Bila nilai matriks tamu tersebut 3-4 hanya perlu diberikan safety briefing, bila nilainya 5-6 maka perlu diberikan safety briefing dan safety induction, bila nilainya 7-8 maka perlu diberikan safety briefing, safety induction dan orientasi. Bila nilainya 9 maka perlu diberikan safety briefing, safety induction, orientasi dan training serta perlu dikeluarkannya HSE Passport untuk tamu. Untuk Tamu dengan hasil evaluasi nilai 3-6 tidak perlu dibuatkan HSE Passport.

Seluruh tamu wajib mengikuti pemenuhan HSE Awareness dan mengisi Formulir Waiver sebagai pengganti pemeriksaan kesehatan. Tamu dengan Skor $\leq 7$ wajib mengisi formulir waiver.

Di dalam formulir waiver tertera masalah kesehatan yang sedang atau telah di alami, mempunyai riwayat operasi atau MRS (masuk rumah sakit) dan kondisi kesehatan terkini (sedang sakit, hamil atau mengonsumsi obat-obatan). Tamu dengan nilai Awareness HSE nya $\leq 7$ wajib mengisi formulir waiver atau dapat pula membawa surat 
pernyataan sehat dari dokter atau rumah sakit. Bila dalam formulir waiver diketahui bahwa tamu tersebut memiliki riwayat penyakit, maka formulir waiver tersebut harus divalidasi oleh dokter. Formulir waiver dapat dipertimbangkan bila didapati kelainan yang sifatnya sedemikian rupa sehingga tidak akan menjadi halangan dalam melaksanakan tugasnya dan tidak membahayakan dirinya.

Pada pekerja, implementasi HSE Passport belum terlaksana dengan baik. Terkadang para pekerja lupa membawa HSE Passport apabila melakukan pekerjaan di field. Menurut indepth interview yang dilakukan peneliti kepada fungsi HSE, para pekerja menganggap implementasi HSE Passport kurang efektif karena sudah ada SIM L (Surat Ijin Masuk Lokasi) yang sudah terlalu banyak permit-nya. Memo penerbitan SIM L telah dilengkapi dengan SIKA dan JSA.

\section{SIMPULAN}

HSE Passport berfungsi memastikan orang yang masuk ke lokasi operasi kerja fit dan kompeten untuk mengurangi terjadinya kecelakaan kerja.

Seluruh pekerja PT. Pertamina EP sudah memiliki HSE Passport. Sebagian besar pekarya/mitra kerja (65\%) belum memiliki HSE Passport. HSE Passport bagi tamu belum pernah dikeluarkan.

Implementasi HSE Passport di PT. Pertamina EP belum berjalan sepenuhnya. Pekerja belum memahami pentingnya HSE Passport. Perlu ada pemahaman yang lebih mendalam terhadap HSE Passport sesuai prosedur. Peraturan tentang HSE Passport belum dilaksanakan secara tegas seperti larangan memasuki lokasi kerja bila tidak membawa HSE Passport. Sehingga banyak pekerja atau bahkan user (atasan pekerja) kurang mengaplikasikan penggunaan HSE Passport.

Pemeriksaan kesehatan pada pekerja dan pekarya/mitra kerja di PT. Pertamina EP dilakukan secara berkala setiap setahun sekali. Pemeriksaan kesehatan ini bertujuan untuk mendapatkan pekerja dengan kondisi sebaik-baiknya. Sedangkan pemeriksaan kesehatan untuk tamu yaitu dengan mengisi formulir waiver untuk tamu yang nilai matriks Awareness HSE nya $\leq 7$. Jika $\geq 7$ harus mengikuti pemeriksaan kesehatan.

Safety briefing, safety induction dan orientasi diberikan pada pekerja/pekarya baru, pekerja/ pekarya mutasi, kontraktor, dan tamu perusahaan. Pemberian training disesuaikan dengan Job Desk pekerja. Training dilakukan refreshment setiap 3 tahun.

\section{DAFTAR PUSTAKA}

HSE Passport Short Term Program for TOT. 2011. PT. Pertamina EP.

Ilvani, Grisma. Nugraheni, Rini. 2013. Analisis Pengaruh Keselamatan Dan Kesehatan Kerja Terhadap Kinerja Karyawan (Studi pada PT. Apac Inti Corpora Bawen Jawa Tengah Unit Spinning 2). Jurnal Studi Manajemen \& Organisasi. Vol. 10, No. 2, Juli, Thn 2013. Universitas Diponegoro.

Peraturan Menteri Tenaga Kerja dan Transmigrasi No. Per.02/Men/1980 Tentang Pemeriksaan Kesehatan Tenaga Kerja Dalam Penyelenggaraan Keselamatan Kerja.

Piri, Sovian. 2012. Pengaruh Kesehatan, Pelatihan dan Penggunaan Alat Pelindung Diri Terhadap Kecelakaan Kerja Pada Pekerja Konstruksi di Kota Tomohon. Jurnal Ilmiah Media Engineering Vol. 2, No. 4, November 2012: Universitas Sam Ratulangi.

Suma'mur, P.K. 2009. Higiene Perusahaan dan Kesehatan Kerja (HIPERKES). Jakarta: Sagung Seto.

TKO Pengendalian HSE Passport No.B-076/ EP5000/2010-S0/Rev.00. 2012. PT. Pertamina EP.

TKO Penerapan HSE Passport NO. B-075/ EP5000/2012-S0/Rev00. 2012. PT. Pertamina EP.

TKO Safety briefing, Induksi Dan Orientasi Aspek HSE NO. B-018/EP8000/2015-SO Rev. 01. 2015. PT. Pertamina EP.

Undang-Undang Republik Indonesia No. 1 tahun 1970 tentang Keselamatan Kerja.

Winarsunu, Tulus. 2008. Psikologi Keselamatan Kerja. Malang: UPT Penerbitan Universitas Muhammadiyah Malang. 